\title{
A experiência do Pibid na UEMA sob os olhares freireanos: objetivos, metas e estratégias de formação profissional do Pibid na UEMA
}

\author{
The experience of pibid in uema under the freirean eyes: objectives, goals and \\ professional training strategies of Pibid at UEMA
}

\author{
Maria Goretti Cavalcante de Carvalho ${ }^{1}$ \\ Deuzimar Costa Serra ${ }^{2}$
}

\begin{abstract}
Resumo
Este texto aborda reflexões sobre a experiência do Programa Institucional de Bolsas de Iniciação à Docência - Pibid, da Universidade Estadual do Maranhão - UEMA, por meio do seu projeto institucional de iniciação à docência (2018), definido por objetivos, metas e estratégias de formação inicial, sob os olhares freireanos voltados para a crítica sobre os saberes da prática docente, na medida em que se torna um profícuo diálogo entre a teoria e a prática - a práxis. Reflete-se sobre a projeção das instituições formadoras, as suas ações para consolidar a iniciação à docência de estudantes de cursos de licenciatura, e as contribuições freireanas para a se pensar a formação inicial com experiências no cotidiano escolar. Pontua-se que o desenvolvimento dos projetos de iniciação à docência depende da sensibilidade e da percepção da singularidade, sobre a ambiência escolar, alinhando-se os seus objetivos a um referencial teórico que discuta as recentes questões educacionais, com vistas à construção de conhecimento escolar, no âmbito da formação inicial. O objetivo é refletir sobre a iniciação à docência, buscando na escola um espaço de formação e problematização dos processos constituintes da práxis educativa. Indica-se que a iniciação à docência pode ser uma experiência dialógica positiva com o ambiente escolar, um espaço próprio de atividades relacionais, como possível ampliação da consciência crítica do professor em formação, sobre a utilização deste espaço de atuação profissional como uma ambiência sensorial para a produção do conhecimento nas práticas docentes.
\end{abstract}

Palavras-chave: Práxis educativa. Paulo Freire. Pibid.

\begin{abstract}
This text addresses reflections on the experience of the Institutional Scholarship Program for Initiation to Teaching - Pibid, of the State University of Maranhão - UEMA, through its

\footnotetext{
${ }^{1}$ Professora Adjunta II do Departamento de Educação e Filosofia, do Centro de educação, Ciências Exatas e Naturais - CECEN, da Universidade Estadual do Maranhão - UEMA. Doutora em História, pela UNISINOS; Mestre em educação e Licenciada em pedagogia, pela UFMA. Docente Permanente do Programa de PósGraduação em Educação da UEMA. goretticavalcante2008@yahoo.com.br

${ }^{2}$ Professora Adjunta II e Diretora do Centro de Estudos Superiores de Codó-CESCD/UEMA; Doutorado em Educação-UFC; Pós-doutorado em Políticas educativas na abordagem da ação pública (Instituto de Educação da Universidade de Lisboa-Portugal). Pesquisadora e Líder do Grupo de Estudos e Pesquisas em Políticas Públicas e Gestão da Educação-GEP-PPGE. deuzimarserra@professor.uema.br
} 


\section{-Revista de Iniciação à Docência, v.6, n.2, 2021- \\ Publicação: dezembro, 2021 - ISSN 2525-4332}

institutional project for initiation to teaching (2018), defined by objectives, goals and training strategies initial, under Freire's perspectives aimed at criticizing the knowledge of teaching practice, insofar as it becomes a fruitful dialogue between theory and practice - praxis. It reflects on the projection of educational institutions, their actions to consolidate the initiation to teaching of undergraduate students, and Freire's contributions to thinking about initial training with experiences in everyday school life. It is pointed out that the development of teaching initiation projects depends on the sensitivity and perception of uniqueness, on the school environment, aligning its objectives with a theoretical framework that discusses recent educational issues, with a view to building school knowledge, in the context of initial formation. The objective is to reflect on the initiation to teaching, seeking in the school a space for training and problematizing the processes that constitute the educational praxis. It is indicated that the initiation to teaching can be a positive dialogic experience with the school environment, a proper space for relational activities, as a possible expansion of the critical awareness of the teacher in training, about the use of this space of professional activity as a sensory environment for the production of knowledge in teaching practices.

Keywords: Educational praxis. Paulo Freire. Pibid.

\section{Introdução}

Este texto trata das relações que se tecem entre a iniciação à docência, os seus objetivos, metas e estratégias de formação inicial, sob olhares freireanos, no âmbito do projeto institucional ${ }^{3}$ do Programa Institucional de Bolsas de Iniciação à Docência (Pibid) da Universidade Estadual do Maranhão (UEMA). Entre estas relações há ações projetadas pela UEMA para oportunizar a iniciação à docência aos estudantes dos seus cursos de licenciatura, por meio de seu projeto institucional, no sentido de fortalecer a formação inicial do docente, alinhada aos saberes fundamentais da prática pedagógica na perspectiva dialógica. Nessa perspectiva, o projeto institucional de iniciação à docência da UEMA afilia-se ao que corrobora Freire, quando nos orienta para o seguinte:

[...] ensinar não é transferir conhecimentos, conteúdos nem formar é ação pela qual um sujeito criador dá forma, estilo ou alma a um corpo indeciso e acomodado. Não há docência sem discência, as duas se explicam e seus sujeitos, apesar das diferenças que os conotam, não se reduzem à condição de objeto, um do outro. (FREIRE, 2016, p.25)

É nesse sentido, que as reflexões sobre a temática da iniciação à docência e do desenvolvimento dos diversos projetos institucionais têm se tornado, ao longo dos últimos anos, um dos campos mais profícuos de pesquisa, análise, reflexões e discussões,

\footnotetext{
3 Projeto institucional de iniciação à docência submetido ao Edital CAPES/Pibid № 07/2018, aprovado e cadastrado na Plataforma Capes de Educação Básica. É o documento organizado na forma determinada pela CAPES/MEC, a ser apresentado pelas IES habilitadas ao Programa Institucional de Bolsas de Iniciação à Docência - Pibid, uma política nacional de formação de professores, conforme as orientações de editais bienais.
} 


\section{-Revista de Iniciação à Docência, v.6, n.2, 2021- \\ Publicação: dezembro, 2021 - ISSN 2525-4332}

razão pela qual diferentes áreas do conhecimento têm analisado essa perspectiva da formação docente. A Pedagogia da Autonomia, obra importante de Paulo Freire (2016), é uma referência para se compreender melhor os fenômenos da prática pedagógica e suas manifestações na produção do conhecimento, assim como para se avaliar os impactos das inserções dos licenciandos no ambiente escolar e as suas relações com os mais diversos elementos sociais, como a cultura, a política e a educação. Nessa perspectiva, faz-se necessário observar nas projeções para a iniciação à docência que:

[...] Quando vivemos a autenticidade exigida pela prática de ensinar-aprender participamos de uma experiência total, diretiva, política, ideológica, gnosiológica, pedagógica, estética e ética, em que a boniteza deve achar-se de mãos dadas com a decência e com a seriedade (FREIRE, 2016, p.26).

Nessa direção, o Projeto Institucional da UEMA desenvolveu-se alicerçado nos princípios norteadores do referido Pibid, cujas linhas principais contemplam a valorização do magistério e a interação de licenciandos com os professores da rede pública de ensino, imprescindível para o conhecimento e vivência, reconhecimento e valorização no/do espaço da escola pública de educação básica, como lugar de construção do conhecimento na formação estética e ética de professores. Tudo isto, "criticamente exercitando a capacidade de aprender" (FREIRE, 2016, p. 27), e desenvolver aquilo que o autor trata de "curiosidade epistemológica".

O referido projeto institucional envolveu áreas de forte impacto pedagógico, uma vez que promoveu a implementação de uma proposta de iniciação didático-pedagógica que articulasse metodologias ativas com práticas inovadoras na inserção dos licenciandos no cotidiano escolar, ao tempo em que desenvolviam reflexões sobre os conhecimentos básicos das áreas envolvidas: Filosofia, Matemática, Língua Portuguesa, Língua Inglesa, Artes, História e Pedagogia. Estas áreas foram reconhecidas com vistas no letramento científico, considerando igualmente outra área que mostra diferente contexto de produção humana, como a história. Nessa oportunidade, os licenciandos dos primeiros períodos dos seus cursos tiveram mais condições reais de laboratório nas escolas da rede pública de ensino, além de estabelecerem um diálogo direto com professores, supervisores e gestores destes contextos de ensino-aprendizagens.

Este texto enfatiza as ações de um projeto de iniciação à docência que ratifica o compromisso de cada educador com a formação integral do cidadão e com a necessidade de incluir o estudante como sujeito principal e protagonista do processo de sua formação docente. Mas, para que esse compromisso fosse fortalecido, em sua integralidade, o docente aprendiz deveria estar assenhoreado dos novos processos de aprendizagem dos saberes da prática docente e das novas circunstâncias socioculturais e políticas que o geraram. Deveria julgar-se autônomo e competente no saber e no saberfazer. E isso só seria possível se as relações estabelecidas entre a escola e a universidade oportunizassem a articulação teoria e prática consciente - a práxis, o que aconteceu. 


\section{Estratégias e objetivos de institucionalização da iniciação à docência}

A Institucionalização da Iniciação à Docência é fato no processo de formação docente da UEMA. O Pibid teve início na IES em 2013, e desde então vem se consolidando como uma política institucional de formação de professores, pela sua natureza formativoreflexiva.

Neste contexto, foram pensadas estratégias de Institucionalização da Iniciação à Docência: - os cursos de Licenciatura desta IES são habilitados e incentivados a valorizarem a Iniciação à Docência e participarem do Pibid, reconhecendo a carga horária das atividades realizadas pelo discente no Programa como horas de prática como componente curricular ou de atividades teórico - práticas; - há designação de servidores para compor a Coordenação Institucional da UEMA, para a elaboração do Projeto de Iniciação à Docência; e - a criação de um Colegiado de Articulação dos Cursos de Licenciatura para discutir, debater e avaliar os efeitos da Iniciação à Docência, na Universidade e na Escola de Educação Básica.

E, ainda objetivando intensificar o diálogo com as escolas para a otimização do uso de diversos espaços formativos da escola no intuito de desenvolver, testar, executar e avaliar estratégias didático-pedagógicas e instrumentos educacionais, a UEMA disponibilizou capacitações para o uso de tecnologias educacionais e diferentes recursos didáticos que resultassem em oportunidades de construção de conhecimentos para professor em formação.

As ações institucionais projetadas para a iniciação à docência na UEMA estão alinhadas aos objetivos do seu Projeto Institucional do Pibid, que contemplam o processo de indução, inserção e fomento da iniciação à docência, à valorização e à qualificação da formação inicial de professores para a educação básica, na articulação teoria e prática, em uma parceria entre as IES e a rede de escolas públicas de educação básica. Tudo isto na prática pesquisadora e na perspectiva de que:

[...] Não há ensino sem pesquisa e pesquisa sem ensino. Esses que fazeres se encontram um no corpo do outro. Enquanto ensino continuo buscando, reprocurando. Ensino porque busco, porque indaguei, porque indago e me indago. Pesquiso para constatar, constatando, intervenho, intervindo educo e me educo. Pesquiso para conhecer o que ainda não conheço e comunicar ou anunciar a novidade (FREIRE, 2016, p. 30).

Com base nesse pensamento freireano, a UEMA organizou o seu Projeto Institucional do Pibid (UEMA, 2018) para incentivar a formação de docentes em nível superior para a educação básica, potencializando no bolsista de iniciação à docência a capacidade de identificar os problemas concernentes à prática educativa, como uma prática docente de indagação, de busca e pesquisa, utilizando o referencial teóricometodológico freireano, cuja linha investigativa convoca o desenvolvimento da formação de professores na superação de limitações que impedem a transformação de práticas 


\section{-Revista de Iniciação à Docência, v.6, n.2, 2021- \\ Publicação: dezembro, 2021 - ISSN 2525-4332}

docentes disponível para compreender suas causas e consequências, e propor alternativas de solução.

Em função disso, cada licenciando foi convocado a assumir e se perceber um pesquisador, alinhado aos seguintes objetivos específicos do referido projeto:

[...] I - contribuir para a valorização do magistério, com uma formação sólida que subsidie a capacidade de relacionamento interpessoal no ambiente de trabalho; II - elevar a qualidade da formação inicial de professores nos cursos de licenciatura, promovendo a integração entre educação superior e educação básica; III - inserir os licenciandos no cotidiano de escolas da rede pública de educação, proporcionando-lhes oportunidades de criação e participação em experiências metodológicas, tecnológicas e práticas docentes de caráter inovador e interdisciplinar que busquem a superação de problemas identificados no processo de ensino-aprendizagem; IV - incentivar escolas públicas de educação básica, mobilizando seus professores como coformadores dos futuros docentes e tornando-as protagonistas nos processos de formação inicial para o magistério; $\mathrm{V}$ - contribuir para a articulação entre teoria e prática necessárias à formação dos docentes, elevando a qualidade das ações acadêmicas nos cursos de licenciatura; VI - contribuir para que os estudantes de licenciatura se apropriem da cultura escolar, construída no magistério, por meio da reflexão sobre saberes, fazeres e peculiaridades do trabalho docente (UEMA, 2018, p. 01).

A inscrição da UEMA no Pibid (Edital CAPES, $n^{\circ}$ 07/2018) deu-se com um Projeto Institucional composto de 8 (oito) subprojetos ${ }^{4}$, nos diferentes níveis da Educação Básica: Educação Infantil, Ensino Fundamental e Ensino Médio, cuja possibilidade era o confronto entre a teoria e a prática na realidade escolar. Este Projeto Institucional de Iniciação à Docência esteve alinhado com todos os objetivos dos seus subprojetos, no sentido de articular e potencializar experiências dos licenciandos no cotidiano escolar. Nesta perspectiva, os subprojetos se articularam consolidando uma unidade de ações no âmbito dos componentes curriculares: Filosofia, Artes, Pedagogia, Letras, História e Matemática, nos contextos das escolas municipais e estaduais de São Luís, Caxias, Bacabal e Timon- MA. Foi uma consolidação dialógica de ações que permitiu o desenvolvimento de aptidões e métodos na aplicação dos conhecimentos, construídos no ambiente acadêmico, na relação entre Universidade e a Educação Básica, no desenvolvimento profissional docente, na formação do professor leitor, no desenvolvimento da atitude docente, na formação do professor pesquisador, na qualificação do ensino e no desenvolvimento de novas metodologias de ensino e do trabalho colaborativo.

Esta unidade do referido projeto foi compreendida na articulação dos diversos subprojetos e respectivas experiências de ensino e de resolução de problemas na sala de aula e dos processos de ensino, com trocas, experiências e vivências práticas nas escolas, bem como intercâmbios entre as Universidades. Nos relatórios de atividades dos

\footnotetext{
${ }^{4}$ Subprojeto corresponde ao conjunto de núcleos de iniciação à docência agrupados por componente curricular ou curso (EDITAL CAPES/Pibid 07/2018).
} 


\section{-Revista de Iniciação à Docência, v.6, n.2, 2021- \\ Publicação: dezembro, 2021 - ISSN 2525-4332}

participantes, nota-se muita curiosidade e expectativa sobre o ofício de ser docente, o que levou a muitos concluírem em "[...] saber que ensinar não é transmitir conhecimento, mas criar as possibilidades para a sua própria produção ou a sua construção” (FREIRE, 2016, p.47).

Para coordenar este projeto institucional, o plano de atividades dos subprojetos foi definido com base nos princípios da iniciação à docência ${ }^{5}$, cujos eixos fundam um trabalho que garantisse a inserção de cada subprojeto, construído coletiva e qualitativamente, com autonomia", para a "leitura de mundo" freireana. Em função disto, foram pensadas as seguintes linhas diretrizes: formação docente, com a construção dos conceitos próprios do processo ensino-aprendizagem, da compreensão de políticas educacionais); grupos de pesquisa, com o rigor necessário para a construção do conhecimento da realidade escolar; organização de estudos sobre o currículo e a relação universidade-escola; e avaliação, em plena conformidade com os princípios da iniciação à docência - Pibid, uma vez que foram desenvolvidas atividades em níveis crescentes de complexidade em direção à autonomia do aluno em formação; valorização do trabalho coletivo e interdisciplinar; objetividade pedagógica para o processo de ensinoaprendizagem, com as devidas críticas aos objetos de conhecimento da Base Nacional Comum Curricular; além de estimular a inovação, a ética profissional, a criatividade, a inventividade e a interação dos pares; e o aperfeiçoamento das habilidades de leitura, de escrita e de oralidade do licenciando.

Enfatiza-se que, embora os objetos de conhecimento e a intencionalidade da BNCC não estejam na perspectiva freireana, é possível seguir as indicações da base pela própria autonomia pedagógica, construída a partir do compromisso e da responsabilidade dos docentes e estudantes. Ratifica-se que há espaços para o trabalho dialógico e para a crítica, com leitura das condições de produção da realidade do processo de ensinoaprendizagem escolar. Além disso, o plano de atividades dos componentes curriculares aponta para a possibilidade de estimular a inovação, a ética profissional, a criatividade, a inventividade e a interação dos pares; e o aperfeiçoamento das habilidades de leitura, de escrita e de oralidade do licenciando.

\footnotetext{
${ }^{5}$ São princípios da iniciação à docência, apresentados pela Coordenação de Aperfeiçoamento de Pessoal da Educação Superior (CAPES): I. o desenvolvimento de atividades em níveis crescentes de complexidade em direção à autonomia do aluno em formação; II. valorização do trabalho coletivo e interdisciplinar; III. intencionalidade pedagógica clara para o processo de ensino-aprendizagem dos objetos de conhecimento da Base Nacional Comum Curricular; IV. estímulo à inovação, à ética profissional, à criatividade, à inventividade e à interação dos pares; e V. aperfeiçoamento das habilidades de leitura, de escrita e de fala do licenciando. (EDITAL CAPES Nº 7/20218, item 9.7.1).

${ }^{6}$ Aqui, podem ser considerados os seus significados comuns: autogoverno, emancipação, independência, liberdade, soberania (HOUAISS, 2003). Estes significados devem ser analisados na esfera filosófica, trazendo as convicções freireanas para as buscas de indícios do escopo do projeto ético kantiano, vez que é estabelecido um imperativo, do qual a razão se fundamenta para o agir autônomo em busca de uma lei que universalize nossas atitudes (KANT, 2006).
} 


\section{-Revista de Iniciação à Docência, v.6, n.2, 2021- \\ Publicação: dezembro, 2021 - ISSN 2525-4332}

Os licenciandos tiveram a oportunidade de utilizar tecnologias da informação e da comunicação, que já são disponibilizadas a serviço dos docentes da UEMA, em face das transformações por que passa a sociedade, ao abrir as portas do ensino superior para múltiplas pessoas e segmentos.

Conforme o Projeto Institucional do Pibid/UEMA (2018), o trabalho foi realizado em grupos dos subprojetos, e considerou as seguintes etapas:

1 - Preparação - reunião inicial com os estudantes, onde foi discutida a proposta do Projeto Institucional de Iniciação à Docência - Pibid, para ser trabalhada em cada dimensão. Na oportunidade, os professores provocaram problematizações por parte dos estudantes, o que gerou temas, que aos poucos foram sendo definidos, articulados com as suas áreas específicas do conhecimento. A organização inicial das atividades ocorreu na perspectiva de que:

[...] nas condições de verdadeira aprendizagem os educandos vão se transformando em reais sujeitos da construção e da reconstrução do saber ensinado, ao lado do educador, igualmente sujeito do processo. Só assim podemos falar realmente de saber ensinado, em que o objeto ensinado é apreendido na sua razão de ser e, portanto, aprendido pelos educandos (FREIRE, 2016, p.27).

Esse processo de aprendizagem, sob os olhares freireanos através dos saberes necessários à prática docente, com rigorosidade metódica, pesquisa, respeito aos saberes dos educandos, criticidade, estética e ética, corporificação das palavras pelo exemplo, risco, etc. (FREIRE, 2016), deu-se na formação de equipes, de acordo com temas escolhidos. Cada equipe tomou ciência e discutiu as ações, específicas de cada subprojeto, que nortearam todas as atividades a serem desenvolvidas ao longo do Projeto Institucional. É importante ressaltar, que um mesmo tema poderia ser investigado nas diversas dimensões, ampliando o conhecimento sobre o mesmo e proporcionando uma continuidade no processo investigativo, ponto principal da Prática como Componente Curricular. Neste sentido, os saberes prévios dos licenciandos foram respeitados, sobretudo, sob o pensamento de Freire (2016, p. 17), “os saberes socialmente construídos na prática comunitária - mas, também, [...], discutir com os alunos a razão de ser de alguns desses saberes em relação com o ensino dos conteúdos".

A etapa de preparação foi fundamental para o sucesso do Projeto Institucional, uma vez que era o momento de socialização, sensibilização e, dependendo da motivação dos alunos, implicaria em resultados mais satisfatórios.

2 - Desenvolvimento - foi o momento em que as equipes realizaram as atividades previstas nos seus subprojetos, dentre as quais se destacam a pesquisa bibliográfica; elaboração de instrumentos de coleta de dados (questionários, formulários, roteiro de observação); a pesquisa-ação; pesquisa-participante; aplicação dos instrumentos de coleta de dados; tabulação e análise dos dados coletados e elaboração de relatórios: da 


\section{-Revista de Iniciação à Docência, v.6, n.2, 2021- \\ Publicação: dezembro, 2021 - ISSN 2525-4332}

investigação e da realização das atividades de regência. Nesta etapa, embora fossem detalhados os pontos importantes de execução, as exigências sobre a apreensão da realidade da iniciação à docência convocaram os licenciandos a experimentarem a sua natureza. O diálogo entre docência e pesquisa é uma relação necessária. Conforme Freire (2016), não há ensino sem pesquisa, pois enfatiza que, "como professor preciso me mover com clareza na minha prática. Preciso conhecer as diferentes dimensões que caracterizam a essência da prática, o que me pode tornar mais seguro no meu próprio desempenho" (FREIRE, 2016, p. 35). Neste sentido, as atividades foram desenvolvidas.

3 - Apresentação dos resultados - os resultados obtidos pelas equipes foram apresentados durante Seminários de Prática, do Encontro de Iniciação à Docência (ENID), evento realizado pela UEMA, como forma de incentivar os seus estudantes a refletirem e valorizarem a Iniciação à Docência. O tema trabalhado foi "A INICIAÇÃO À DOCÊNCIA: coformação, aprendizagens e vivências pedagógicas”, com quatro eixos temáticos: 1 Processos de ensino e aprendizagem - com ênfase na inovação tecnológica, metodológica, práticas docentes e práticas aplicadas na alfabetização e no letramento científico; 2 - Políticas públicas e identidade docente - com ênfase em referenciais políticos e epistemológicos da profissão; 3 - Políticas educacionais, avaliação e currículo com ênfase nas novas demandas curriculares para identidade docente e o processo de avaliação no cotidiano das escolas de educação básica; e 4 - Educação, diversidade e inclusão social - com ênfase na relação entre fundamentos teóricos e metodológicos.

A participação dos licenciandos contemplou desde a organização do referido evento até a sua consolidação, com a exposição dos resultados de suas pesquisas, utilizando diversas formas, como: comunicação oral, pôster, exposição, etc.

Todas as etapas citadas foram realizadas sob a orientação dos coordenadores de áreas, com a colaboração dos supervisores das escolas que aderiram ao Pibid através de edital da CAPES.

2 - Avaliação - em relação aos estudantes, o processo avaliativo da Prática se deu ao longo da realização das etapas da pesquisa desenvolvidas, considerando o envolvimento em cada etapa. Foram utilizados os critérios de autonomia, curiosidade, iniciativa, respeito, responsabilidade, envolvimento grupal, pontualidade no cumprimento do cronograma estabelecido, cientificidade dos documentos elaborados (projeto, instrumentos de coleta de dados, relatório, roteiro da apresentação oral, etc.), fundamentação teórica e oralidade na apresentação durante o seminário, além da autoavaliação. Em relação aos docentes, foram realizadas reuniões, tendo como base o diálogo para a mediação do conhecimento e das relações entre os atores e suas expectativas sobre a experiência no Pibid, além de depoimentos dos alunos e autoavaliação:

[...] A experiência escolar no desenvolvimento do projeto e realização das atividades foi muito enriquecedora para a formação docente, as atividades realizadas foram planejadas a partir de discussões sobre objetivos de 


\section{-Revista de Iniciação à Docência, v.6, n.2, 2021- Publicação: dezembro, 2021 - ISSN 2525-4332}

aprendizagem e modos de ensino. Ressaltamos então, um contínuo artifício de discussões e atividades, mantendo em andamento a pesquisa. (Relato de Experiência no Pibid. Núcleo de Pedagogia - Alfabetização. Timon - MA, 2018).

No contexto da execução do Projeto Institucional do Pibid (2018), notou-se que se aprende muito com a escola e com os saberes experienciais dos professores, como Tardif (2014) nos ensina. Para o autor não há separação entre relação teoria e prática, pois, na prática há teoria e na teoria há prática, e que são os atores, os sujeitos, que dão vida a prática docente.

Destaca-se outra contribuição da iniciação à docência que é a ampliação da consciência sobre a pesquisa universitária na área da educação e na prática do ofício de professor. Esta deve ser regida pela relação entre teoria e prática, pois ambas as áreas são portadoras e produtoras de práticas e de saberes, de teorias e de ações, e ambas comprometem os atores, seus conhecimentos e suas subjetividades. Nessa perspectiva, a relação entre a pesquisa universitária e o trabalho docente nunca é uma relação entre uma teoria e uma prática, mas uma relação entre atores, entre sujeitos cujas práticas são portadoras de saberes (TARDIF, 2014, p. 230). Neste sentido, Zeichner (2003) considera a necessidade de o professor atuar como prático reflexivo, e valoriza tanto as teorias pessoais como as teorias ditas "elaboradas" pela Universidade.

\section{Metas do projeto de iniciação à docência (2018)}

As metas são os valores que a UEMA buscou a partir dos indicadores do referido projeto. Podem-se citar as cinco metas definidas:

[...] 1 - Elevação da qualidade da formação do professor em nível superior a partir da articulação entre teoria e prática; 2 - Planejamento e execução de atividades pedagógicas, com criticidade sobre a profissão docente, desenvolvidas nos diferentes espaços escolares (salas de aula, laboratórios, espaços recreativos desportivos, ateliês e secretarias; 3 - Compreensão crítica dos objetivos presentes na BNCC, sua estrutura organizacional e mudanças ocorridas a partir de sua aplicação no currículo e organização das atividades pedagógicas dos diferentes componentes curriculares; 4 - Desenvolvimento e aperfeiçoamento das habilidades de leitura, escrita e fala por meio de propostas de inovação metodológica e recursos didáticos para as diferentes áreas do conhecimento e componentes curriculares da educação básica; e 5 - Compreensão e análise do contexto educacional, onde foram realizadas as atividades dos subprojetos por meio de observações, análises de documentos e participação nas instâncias colegiadas da instituição escolar. (UEMA, 2018, p. 3)

A meta mais importante foi a "elevação da qualidade da formação do professor em nível superior a partir da articulação entre teoria e prática", a partir da inserção do maior número possível de licenciandos no cotidiano de escolas parceiras, pela mobilização institucional, através de editais de seleção de discentes, realizada pelos professores coordenadores de área. Foram inseridos 193 (cento e noventa e três) 


\section{-Revista de Iniciação à Docência, v.6, n.2, 2021- \\ Publicação: dezembro, 2021 - ISSN 2525-4332}

bolsistas e muitos voluntários de oito cursos de três campi da UEMA: Pedagogia, Letras (Língua Inglesa), História, Filosofia, Artes, do Campus São Luís-MA; Letras (Língua Portuguesa), do Campus de Bacabal - MA; Matemática, do Campus de Caxias - MA; e Pedagogia, do Campus de Timon - MA, nos contextos das escolas municipais e estaduais maranhenses.

Além desta principal meta, outras fizeram parte do referido projeto, como: planejamento e execução de atividades pedagógicas, com criticidade sobre a profissão docente, desenvolvidas nos diferentes espaços escolares (salas de aula, laboratórios, espaços recreativos desportivos, ateliês e secretarias. O objetivo dessa meta foi mobilizar os estudantes bolsistas, voluntários e supervisores, para planejarem as suas ações com rigor, responsabilidade, conforme as suas habilidades e competências de cada componente curricular.

Foi necessária a prática de leitura para o aperfeiçoamento de habilidades da escrita e oralidade, com atividades de produção de textos sobre as temáticas trabalhadas, com apresentações orais de seus trabalhos. Somado a isso, houve a realização de importantes experiências com a articulação entre teoria e prática, manifestadas em expressões de autonomia diante da formação de identidade docente. Nessa perspectiva, a formação inicial de futuros professores da educação básica deu-se em uma sistemática definida de produção de materiais didáticos, grupos de estudos, registros escritos de atividades pedagógicas, relatórios sobre práticas elaboradas e aplicadas.

Durante a execução do projeto institucional do Pibid/UEMA (2018), muitas discussões buscaram compreender o nível de valorização do magistério, como outra meta importante. Em função disto, foram realizados debates, intervenções pedagógicas, estudos que tratam da valorização do papel do docente na sociedade, além de realização de seminários para a discussão dos desafios a serem enfrentados, acerca da profissão docente, e possíveis soluções. Com esse propósito, e sob os olhares freireanos, pensar na prática educativa-crítica, como tarefa mais importante, pois a partir desta é possível:

[...] propiciar as condições em que os educandos em suas relações uns com os outros e todos com o professor ou a professora ensaiam a experiência profunda de assumir-se. Assumir-se como ser social e histórico, como ser pensante, comunicante, transformador, criador, realizador de sonhos, capaz de ter raiva porque capaz de amar. (FREIRE, 2016, p.46)

No mesmo passo, outra meta igualmente importante foi potencializar a articulação entre a Universidade e as Escolas parceiras, com a estratégia da realização de encontros semanais e reuniões mensais entre estas instituições para refletirem o papel de cada uma na formação inicial dos licenciandos, respeitando a sua curiosidade e a autonomia do pensamento de cada um. E aqui, incansavelmente traz-se Paulo Freire, para não se perder de vista que: "O respeito à autonomia e à dignidade de cada um é um 


\section{-Revista de Iniciação à Docência, v.6, n.2, 2021- \\ Publicação: dezembro, 2021 - ISSN 2525-4332}

imperativo ético e não um favor que podemos ou não conceder uns aos outros" (FREIRE, 2016, p. 66).

Nos encontros semanais, participavam os estudantes bolsistas, voluntários e supervisores nas escolas, para planejarem, pesquisarem e consolidarem atividades de pesquisa, vivências nos espaços escolares para o reconhecimento de suas funções. Nesse sentido, os estudantes reconheciam a importância da secretaria da escola, do espaço da coordenação pedagógica, das salas de aula, do pátio de vivência dos alunos das escolas e reconhecer o potencial de atividades nestes espaços, para observar as relações de aprendizagem em outros espaços fora da sala de aula. Outras atividades precisaram da orientação dos coordenadores das áreas e dos gestores das escolas para o devido reconhecimento das condições de planejamentos, conforme a dinâmica curricular de cada escola. Mensalmente, a coordenação institucional reunia com os coordenadores de área e os supervisores a fim de ampliarem a consciência sobre a execução do projeto institucional.

A articulação entre teoria e prática foi uma meta imprescindível do projeto, e teve como estratégia a sistematização de materiais educativos, elaboração de sequências didáticas, produção de páginas virtuais, produção de oficinas, grupos de estudos sobre metodologia de ensino e teorias da aprendizagem, relatos de experiências que tratem de conteúdo específico de modo prático. A produção de materiais didáticos, grupos de estudos, registro escrito de atividades pedagógicas, relatórios sobre práticas elaboradas e aplicadas foi uma das estratégias da meta relacionada ao produto final do projeto.

As atividades contemplaram o estudo do contexto educacional. Os participantes de cada subprojeto buscaram compreender o contexto sociocultural das escolas para o devido planejamento de ações investigativas e de intervenções didático-pedagógicas. $\mathrm{E}$ para o desenvolvimento de ações nos diferentes espaços escolares - como salas de aula, laboratórios, bibliotecas, espaços recreativos e desportivos, ateliês, secretarias, foi muito importante a construção do diálogo com os conceitos para a compreensão da realidade escolar, além da articulação dos membros do programa com a comunidade escolar no desenvolvimento de ações em outros espaços além da escola, como ambientes culturais, científicos e tecnológicos, físicos ou virtuais.

Nessas ações, houve significativa participação dos estudantes bolsistas e voluntários e dos supervisores nas atividades de planejamento e no projeto pedagógico da escola, bem como participação nas reuniões pedagógicas e órgãos colegiados; análise do processo de ensino-aprendizagem dos conteúdos específicos ligado ao subprojeto e também das diretrizes e currículos educacionais da educação básica.

Incluem-se nessa abordagem outros pontos necessários, como a leitura e a discussão de referenciais teóricos educacionais contemporâneos e de formação para o estudo de casos didático-pedagógicos; cotejamento da análise de casos didáticopedagógicos com a prática e a experiência dos professores das escolas de educação 
-Revista de Iniciação à Docência, v.6, n.2, 2021-

Publicação: dezembro, 2021 - ISSN 2525-4332

básica, em articulação com seus saberes sobre a escola e sobre a mediação didáticas dos conteúdos. Para este momento, além da perspectiva de educação pensada por Paulo Freire, foram utilizadas as construções teóricas de Antônio Nóvoa, Maurice Tardif, Selma Garrido Pimenta, Dermeval Saviani e outros que estiveram nesses diálogos acerca da formação docente e os seus saberes necessários.

O desenvolvimento, testagem, execução e avaliação de estratégias didáticopedagógicas e instrumentos educacionais, incluíram metodologias ativas, o uso de tecnologias educacionais e diferentes recursos didáticos, como jogos educativos, oficinas de ambientação virtual de aprendizagem no Núcleo de Tecnologia para a Educação UEMANET, dentre outros tão quanto importantes. Além disso, houve a sistematização e registro das atividades realizadas no âmbito do subprojeto, com previsão de um artigo ou relato de experiência, como produção individual de cada discente. Em função disso, os estudantes foram orientados para a organização rigorosa de suas ideias sobre os saberes de sua profissão, com fundamentos teóricos, mas com a convicção de que "[...] testemunhar a abertura aos outros, a disponibilidade curiosa à vida, a seus desafios, são saberes necessários à prática educativa" (FREIRE, 2016, p. 26).

As metas e estratégias do Projeto Institucional de Iniciação à Docência da UEMA (2018) estiveram em uma articulação necessária entre os seus subprojetos, com saberes imprescindíveis para a sua realização: a ética, que é a própria dignidade do aprender problematizado; a estética, que é a "boniteza" do processo de aprendizagem; a autonomia, aprendizado sem pressão, e a criticidade, que é o primeiro passo para a autonomia do pensamento.

\section{Diálogo entre a UEMA, os subprojetos e o projeto de iniciação à docência}

Os subprojetos foram desenvolvidos de modo que as experiências e saberes construídos por meio de cada um deles pudessem ser compartilhados entre os demais, culminando, assim, no realinhamento dialógico das atividades comuns e no fortalecimento do Projeto de Iniciação à Docência proposto pela instituição. A ideia consistia em valorizar as aprendizagens significativas, referentes aos temas transversais da vida prática, quanto à formação de professores, no âmbito das realidades educacionais contextualizadas, com respeito aos saberes dos educandos, construídos socialmente pelos estudantes na prática comunitária, e à escola, com a compreensão de:

[...] o dever de não só respeitar os saberes com que os educandos, sobretudo os das classes populares, chegam a ela - saberes socialmente construídos na prática comunitária - mas também, [...] discutir com os alunos a razão de ser de alguns desses saberes em relação com o ensino dos conteúdos (FREIRE, 2016, p. 17). 
Com efeito, os encontros de discussões teórico-metodológicas se mostraram necessários aos direcionamentos na busca de fazer articular os subprojetos. Ao envolver a coordenação institucional, docentes coordenadores de áreas, supervisores e representações de estudantes bolsistas do Pibid de cursos distintos, tais espaços de discussão tenderam a proporcionar ainda mais inteligibilidade ao Projeto Institucional. De tal modo, vislumbraram-se três modalidades de encontros: a primeira, por área do conhecimento - Linguagens, Matemática, Ciências da Natureza e Ciências Humanas; a segunda, de âmbito intermunicipal; a terceira, por fim, de extensão geral, ou seja, um fórum composto por agentes de todos os subprojetos. Assim, os dilemas, desafios e paradoxos educacionais, identificados em investigação temática, se tornaram temas geradores de discussões sobre violência escolar, evasão escolar, metodologias de ensino, diversidade e inclusão. Estas investigações foram iniciadas nos primeiros contatos dos bolsistas e voluntários do Pibid no cotidiano escolar, e se desenvolveram com maior intensidade com as orientações dos coordenadores de áreas e dos supervisores de iniciação à docência nas escolas, com leituras e discussões.

A articulação dialógica dos subprojetos efetivou-se na sua perspectiva de unidade da teoria e da prática, no diálogo das áreas do conhecimento, pressupondo relações de interdependência e reciprocidade, por meio de "[...] um processo complexo, no qual, muitas vezes passa-se da prática à teoria e outras desta à prática”. (VASQUEZ, 1997, p. 233).

\section{Estratégia de articulação entre teoria e prática}

A articulação deste Projeto de Iniciação à Docência com as práticas como componente curricular alinhou-se, conforme a Resolução CNE/CP 02/2015, que definiu as novas diretrizes para os cursos de licenciatura, e por meio da qual estabeleceu-se que os Cursos integralizarão: $\S 1^{\circ}$ Os cursos [...]: I - 400 (quatrocentas) horas de prática como componente curricular, distribuídas ao longo do processo formativo; [...] (BRASIL, 2015, p.11). A Prática como Componente Curricular nas licenciaturas, conforme a Resolução CNE/CP 02/2015, enfatiza a importância da relação entre a teoria e a prática e um trabalho articulado durante a formação de professores, e dão sustentação às Normas Gerais de Graduação da UEMA e à criação e aprovação, por meio da Resolução n. 1264/2017 CEPE/UEMA, as Diretrizes Curriculares para os seus Cursos de Licenciatura.

Com base nestes dispositivos legais, o referido projeto institucional defendeu que a Prática é o modo pelo qual as ações seriam realizadas, cujo conteúdo seria sustentado por uma teoria. Portanto, a realidade da iniciação à docência, no chão da escola, foi configurada no movimento constituído pela prática e pela teoria em uma relação de interdependência, na qual a busca do fazer algo deveria estar na procura de conceituar, significar, (re) significar, dando sentido ao fazer pedagógico.

A Prática como Componente Curricular se constituiu, no Projeto, na formação mediante a relação educação - trabalho, estabelecendo o vínculo entre a teoria em cada 
área do conhecimento e sua articulação com os conteúdos e métodos trabalhados nos primeiros períodos, integrando os componentes curriculares: o acadêmico, o laboral e o investigativo, a partir do ingresso do aluno na realidade escolar, desde o segundo período dos cursos de licenciatura. Estes foram os elementos articuladores entre teoria e prática e qualificadores da formação inicial e da (futura) ação docente, na qual professores e alunos são protagonistas desse fazer. Nesse sentido, os aspectos acadêmico, laboral e investigativo também ampliaram a consciência sobre a efetiva aproximação da UEMA com as escolas de educação básica, além da reflexão sobre os processos de formação inicial de docentes no contexto escolar.

Os Cursos de Licenciatura da UEMA inseriram nos seus projetos a Prática como Componente Curricular, organizada nas seguintes dimensões: a Político-Social; a Educacional; a Escolar; e a Docente. Estas dimensões estão articuladas com as áreas específicas de cada curso de licenciatura. Na articulação estabelecida verticalmente, entre as dimensões da prática realizada em cada curso, os estudantes já desenvolvem a pesquisa e observação dos processos, procedimentos e práticas educativas e escolares. Neste sentido, as Atividades Práticas de Componentes Curriculares - APCC justificaram o Projeto Institucional do Pibid - UEMA, através das áreas do conhecimento: Filosofia, Arte, Pedagogia, Letras, História e Matemática. Portanto, a Prática foi defendida no Projeto como instrumento de integração e conhecimento do licenciando com a realidade social, política, econômica e do trabalho de sua área/curso, como instrumento de iniciação à pesquisa e ao ensino, e como instrumento de iniciação profissional.

Isto posto, orientados por este Projeto Institucional de Iniciação à Docência (2018), os coordenadores de áreas e os supervisores proporcionaram as atividades práticas com os seus estudantes, a partir de temáticas definidas previamente, e que serão pesquisadas aprofundando os conteúdos, preferencialmente, os relacionados às atividades teórico-práticas dos cursos de licenciatura. Neste sentido, para a operacionalização da Prática como Componente Curricular, inicialmente, foram necessárias reuniões com os envolvidos no Projeto, com o objetivo de definirem os temas a serem investigados e explorados pelos estudantes, considerando as dimensões: político-social, educacional, escolar, docente e discente. Nesta perspectiva, foram definidos os mais importantes temas, quais foram: Educação e Trabalho, Educação Infantil, Educação Patrimonial, Educação e Pluralidade Cultural, Financiamento da Educação, Educação Especial, Educação de Jovens e Adultos e outros temas que a equipe considerou importantes naquele período de formação.

\section{Contribuições do Pibid para os cursos de licenciatura da IES}

O aperfeiçoamento da formação prática nos cursos de licenciatura da UEMA ocorre com a participação dos estudantes, nestes projetos, em atividades de planejamento, observação e execução de ações nos diferentes espaços escolares. É uma 


\section{-Revista de Iniciação à Docência, v.6, n.2, 2021- \\ Publicação: dezembro, 2021 - ISSN 2525-4332}

oportunidade para que os estudantes compreendam ativamente as referidas atividades, com consciência e autonomia em conjunto com os coordenadores e supervisores.

Nesse enfoque, outra contribuição importante refere-se à crítica epistemológica aos objetos de conhecimento da Base Nacional Comum Curricular (BNCC) e a relação com as atividades desenvolvidas em cada subprojeto. Oportunamente, no projeto institucional de 2018, os bolsistas, juntamente aos coordenadores de área e supervisores, alinharam um estudo do contexto educacional, por meio de análise dos documentos que orientam as ações da escola, além da participação e acompanhamento das instâncias colegiadas da escola, que constituem a organização do trabalho pedagógico da instituição escolar: Conselho escolar, Conselho de classe, Grêmio Escolar, Reuniões de pais e professores. Nesse sentido, uma contribuição deste projeto esteve no desenvolvimento e realização de atividades com intencionalidade pedagógica clara para ensino-aprendizagem e criticidade sobre os objetos de conhecimento da BNCC. A compreensão analítica dos objetivos presentes na BNCC, sua estrutura organizacional e mudanças ocorridas a partir de sua aplicação no currículo e a organização das atividades pedagógicas dos diferentes componentes curriculares, também contribuíram para o aperfeiçoamento da formação prática e crítica nos cursos de licenciatura da UEMA.

Essa abordagem inclui outro ponto igualmente importante para o aperfeiçoamento da formação prática nos cursos de licenciatura da UEMA que são os estudos e análises do Projeto Político-pedagógico e Regimento Escolar das escolas partícipes do referido projeto institucional. Através desses estudos e análises, tornou-se mais segura a realização de diagnóstico sobre a comunidade escolar por meio de observações e reflexões para levantar as necessidades das escolas. A apresentação de planejamento e execução de atividades pedagógicas, além da realização das observações e desenvolvimento de ações nos diferentes espaços escolares (salas de aula, laboratórios, espaços recreativos desportivos, ateliês e secretarias) contribuíram para a compreensão de questões basilares da realidade escolar, principalmente em relação aos aspectos: organização pedagógica e administrativa, relação com a comunidade (escolar e local) e políticas públicas para a educação.

Os estudantes tiveram a oportunidade de aperfeiçoarem as suas habilidades de leitura de textos, "leitura de mundo", escrita e expressões orais sobre as suas percepções, uma vez que foram constantemente provocados a exercitar tais habilidades, com as elaborações de relatórios, autocorreção, fichamentos e apresentações orais de trabalhos científicos. Neste sentido, foram selecionadas as leituras de textos que apontassem explicações e aproximações com a leitura da realidade escolar, e seus contextos. Em função disso, houve o exercício da escrita acadêmica e o desenvolvimento da oralidade nas apresentações orais dos trabalhos. A contribuição foi notada nos subprojetos quando os estudantes organizaram e ministraram oficinas e minicursos de leitura e produção textual no ENID de 2019, bem como organização de grupos de estudos de fundamentos teórico-metodológico sobre as temáticas relacionadas à docência e 


\section{-Revista de Iniciação à Docência, v.6, n.2, 2021- \\ Publicação: dezembro, 2021 - ISSN 2525-4332}

criação de grupos de leitura e de estudos, dentre outros recursos, enfatizando a expressão oral e posturas corporais.

A contribuição do projeto para a formação prática dos estudantes dos cursos de licenciatura da UEMA está muito fortemente em induzi-los e inseri-los no cotidiano escolar, levando-os a participarem, desde o início do curso, do processo de investigação, reflexão, problematização, análise e intervenção no cotidiano escolar, favorecendo a melhoria da formação docente e preparando o discente para o mundo do trabalho.

Nessa oportunidade, as disciplinas denominadas de conteúdo específico e as pedagógicas foram refletidas no decorrer de todo o projeto, conforme Schön (1992, p. 90), sobre a epistemologia da prática, para a indispensabilidade de interligar pesquisa e ensino nos cursos de formação de professores, atribuindo ao docente a natureza de pesquisador de sua prática, “... em um processo contínuo de reflexão-ação-reflexão”. No mesmo passo, foram provocados para desenvolverem as suas "curiosidades epistemológicas", tão referendadas por Paulo Freire.

A partir das ações desenvolvidas pela UEMA, através dos seus cursos de licenciatura, afirma-se que o projeto de Iniciação à Docência, alinhado às dimensões práticas curriculares, é considerado como uma contribuição para a formação docente e espaço de articulação entre a academia e as escolas da rede pública de ensino, e pesquisa e ensino na educação básica, possibilitando a integração da teoria e prática, tornando-se assim, conforme Springer, Araújo Júnior e Ferretti (2016), um dos elos significativos do currículo.

Os licenciandos tiveram a oportunidade de conhecer o projeto político pedagógico das escolas, de participar das reuniões pedagógicas e de ouvir a comunidade escolar e local sobre suas necessidades educacionais. Foi uma oportunidade importante de desenvolvimento do respeito na relação universidade-escola para que pudesse acontecer de forma harmoniosa, pois, foi planejado um trabalho coletivo com atenção e valorização no que havia de particular nas escolas, sem a pretensão de impor à escola ideias de intervenção, de modo a desvalorizar ou desclassificar todo um trabalho já construído pela equipe escolar. Este é um aprendizado ímpar para a iniciação à docência.

\section{Considerações finais}

O projeto de iniciação à docência da UEMA, orientado pelos princípios e objetivos do programa nacional de formação inicial de professores, desenvolveu-se em diferentes realidades do contexto educacional maranhense, mais especificamente no que se refere aos municípios situados em diferentes regiões do estado do Maranhão. Foi uma experiência de problematizações na busca de condições de aprendizagem, nas quais as diferenças foram valorizadas, e todos foram convocados a colaborar uns com os outros 
para efetivação dos objetivos, reinventar e inovar os conhecimentos nos diferentes contextos.

Neste sentido, a UEMA projeta os seus objetivos, metas e estratégias de formação inicial, no seu projeto institucional do Pibid, com destaque no seu desenvolvimento em uma perspectiva dialógica que trata dos conceitos construídos, a partir da ética crítica sobre a prática docente, sob olhares freireanos, de como atuar na realidade com amorosidade autêntica em profícuo diálogo entre teoria e prática - a práxis.

Suprimindo-se os aspectos mais isentos da proposta nacional, criaram-se caminhos para trilhar uma projeção mais dialógica e humana, como política de formação da UEMA, tendo como eixo norteador os saberes necessários à prática educativa, como bem afirma Freire (2016), que o ensino exige: rigorosidade metódica, pesquisa, respeito aos saberes dos educandos, criticidade, estética e ética, diálogo, humildade, corporificação das palavras pelo exemplo, risco, dentre outros que, sobretudo exige reflexão crítica sobre a prática na perspectiva da formação com autonomia.

Esse olhar freireano revela que essa construção é coletiva e se dá nas relações entre os atores, ensinantes e aprendentes. $E$, na experiência com o Projeto, tanto a proposta nacional quanto a institucional foram complementares, construídas nelas e delas com o trabalho dos participantes do projeto institucional de iniciação à docência, da UEMA, em 2018.

Nessa arena, as contribuições freireanas para se pensar a formação inicial de professores, ratifica-se que, a formação e as experiências no cotidiano escolar foram vividas com sensibilidade e singularidade. A historicidade, a totalidade, a dialogicidade e a problematização sobre o espaço escolar foram imprescindíveis para o reconhecimento valorativo da formação e o desenvolvimento da autonomia. Esses princípios são muito fortes no pensamento freireano e deram ânimo ao referido projeto institucional, além de acionarem a ampliação da consciência crítica dos professores em formação.

Portanto, este texto é uma contribuição para reflexões de temas, como autonomia pedagógica, dialogicidade, problematização, docência com pesquisa, sempre atuais e pertinentes à formação inicial de professores, especificamente no âmbito dos programas nacionais de formação inicial à docência - Pibid, considerados como vias importantes de política pública de formação profissional no Brasil, tendo como base os pressupostos teóricos e metodológicos de Paulo Freire.

\section{Referências}

BRASIL. Base Nacional Comum Curricular (BNCC). Educação é a Base. Brasília, MEC/CONSED/UNDIME, 2018. Disponível em: 568 http://basenacionalcomum.mec.gov.br/images/BNCC_publicacao.pdf. Acesso em: 02 de jul. 2020. 
CONSELHO NACIONAL DE EDUCAÇÃO CONSELHO PLENO. RESOLUÇÃO N 2: RESOLUÇÃO № 2, DE $1^{\circ}$ DE JULHO DE 2015. Brasília: Ministério da Educação, 2015.

FREIRE, P. Pedagogia da autonomia: saberes necessários à prática educativa. 1. ed. São Paulo: Paz e Terra, 2016.

HOUAISS, I. A. Dicionário Houaiss sinônimos e antônimos. 3. ed. Rio de Janeiro: Objetiva, 2011.

KANT, I. Crítica da Razão Prática. Tradução: Antonio Carlos Braga. São Paulo, SP: Editora Vozes, 2016.

SPRINGER, K. S. JÚNIOR, A. M. de A., FERRETTI, O. E.. O estágio supervisionado na formação de licenciados em geografia na UFSC: compartilhando experiências. In: Movimentos para ensinar Geografia - oscilações / organização de Antonio Carlos Castrogiovanni [et al.]. - Porto Alegre: Editora Letra1, 2016. 312p.

SCHÕN, D.A. Formar professores como profissionais reflexivos. In: NÓVOA, A. (Org.) Os Professores e a sua Formação. pp77-91, Lisboa: Pub. Dom Quixote, 1992.

TARDIF, M. Saberes docentes e formação profissional. 17. ed. Petrópolis, RJ: Vozes, 2014. UNIVERSIDADE ESTADUAL DO MARANHÃO. Coordenação Institucional do Pibid. Projeto Institucional de Iniciação à Docência. Edital CAPES Nº 07/2018. São Luís: PROG, 2018.

Disponível: http://www.pibid.uema.br/wp-content/uploads/2020/01/projeto-institucionalPibid-2018.pdf. Acesso em: 10 de nov. de 2021.

VÁSQUEZ, A.S. Filosofia de práxis. Rio de Janeiro, RJ: Paz e Terra, 1977.

ZEICHNER, K.M. A formação reflexiva de professores: ideias e práticas. Lisboa: Educa, 2003. 